\section{APPRENTICESHIP AND CONSCRIPTION.} To the Editor of THE LANCET.

SIR,-May I draw the attention of your readers to a pamphlet which I have written, entitled "Apprenticeship $v$. Conscription," which purports to show how we can save our youths, the future "English race," from growing up untrained, undisciplined, and often in consequence vicious and criminal. Any of your readers who care to write can obtain a copy free from Messrs. Stanbrook and Sons, Herne Bay.

Although written some years ago, the present time and the next year or two is the opportunity to be preparing for "after the war." Old conditions are changing, new ideas are developing, the land is being ploughed more deeply than ever before, and when the longed-for peace arrives and reconstruction begins some definite plan must be ready to our hand or we shall sink back to lack of method, and instead of progress the present wicked waste of our children and youths will be perpetuated.-I am, Sir, yours faithfully,

Herne Bar, July 12th, 1915. R. C. T. Evans.

\section{THE RIGHT-SIDED MURMURS OF MITRAL STENOSIS. \\ To the Editor of THE LANCET.}

SIR,-In what he terms his "old-fashioned paper," which appears under the above title in THE LANCET of July 3rd, and for which no apology is necessary on account of its maintenance of a clinical method only too rarely seen of late, Sir James Goodhart, speaking with authority and from a ripe experience, refers to many points, both interesting and valuable, which will repay study. The comparative rarity of dextral valvular lesions not of congenital origin is of itself a matter of interest. Indeed, those who discussed the subject were at one time accused of entering upon a "region of romance." The quality of the blood and the nature of the circulation in the venous heart must be the factors which secure a comparative immunity of the adult right heart from valvular disease, and of these the nature of the cicculation is probably the more important. For such non-congenital lesions as are met with in the right heart are chiefly due to infection, and the comparative frequency of congenital disease occurs at a time when the right heart is the chief driving power in the circulation. With the establishment of aerial respiration the right heart is relieved of much of its labour and the lungs themselves become an important factor in promoting the circulation through the venous heart, which loses, in proportion to this relief, both aspirative and propulsive power. I am glad to note Sir James Goodhart's reference to the aspirative power of the heart of which too little has been heard of late, but which, like many "old-fashioned" notions, because true and important, will probably soon be discussed again.

We may take it that the occurrence of a leak through the pulmonary arterial cusps in mitral stenosis is no longer doubtful although not common, for it requires powerful "back-pressure," to use another old and true but largely disused expression, to overcome the resistance of the undamaged pulmonary semilunar cusps. But we know that anatomically and physiologically some regurgitation through the tricuspid ralve may be regarded as normal, and it is only when a degree of hypertrophy has enhanced the power of the right ventricle or when narrowing or rigidity has impaired the distensibility of the right atrio- ventricular orifice, that a tricuspid bruit becomes established.

It is in his discrimination of a tricuspid from a mitral systolic bruit in mitral stenosis that the chief clinical interest of Sir James Goodhart's paper consists. The tricuspid, like the pulmonary arterial area, but less so, lay long in the "region of romance," but the power of the right heart to generate a bruit of tricuspid regurgitation must be admitted. I have myself followed such a bruit from its genesis to its extinction. The case was one of sarcoma of the heart published in THE LANCET of Jan. 9th, 1909, in which the neoplasm first fixed the atrio-ventricular ring or a part of it, when a loud and rough systolic bruit as harsh as any mitral murmur was established and was traceable round the right chest, just as a loud mitral bruit may be to the left, and later, when the right ventricle became fixed by the disease, was altogether abolished, the patient living for a considerable length of time on her left heart alone.

In pointing out the silence and displacement of the mitral area in some cases of left atrio-ventricular stenosis and the occupation of the left præcordium by a systolic bruit of tricuspid origin Sir James Goodhart has done good. service. If not altogether new, this is, as he remarks, "an old wine that a good many apparently have not had the pleasure of tasting." As he also states, it is important for therapeutic reasons. When such a bruit is established the aspiratory forces which assist the circulation through the venous heart are impaired. The pulmonary arterial circulation is impeded by the checked outflow of the pulmonary venous circula. tion and rendered still more tense by the exagger. ated aspirative action of the lungs on the rightheart blood. The initial failure is in left-heart aspiration and propulsion and the vicious cycle established in pulmonary stasis, dextro-cardiac repletion, and impeded venous return.

As Withering remarked when writing of digitalis, it is more difficult to narrate the effects of a remedy than to describe a disease, but there has for long been an impression that the digitalis group has not fulfilled expectations in certain conditions of disease of the right heart and also in some phases of aortic regurgitant disease. There are no doubt many cases both of mitral stenosis and of aortic regurgitation which are saved by the bold use of digitalis. It would occupy too much space to deal with this matter fully here, but there are unquestionably other cases of both diseases in which digitalis is detrimental and in a manner not satisfactorily explained by the assump. tion of an idiosyncrasy on the part of the patient. The cases which Sir James Goodhart describes and which showed the quasi-mitral but really tricuspid murmur in mitral stenosis, were not moribund or even greatly distressed, for they lived for considerable periods after its detection. Although left-heart obstacle was steady in them, right-heart effort was well sustained. This is the delicate balance, in my opinion, which is apt to be easily upset by the unreflecting use of digitalis. The left heart of such a case is one in which there is not a capacious unemptied left ventricle, but an im. perfectly filled one, and the action of digitalis has not, as it has appeared to me, had the effect of emptying a surplus of blood into the systemic arteries, but of diminishing the capacity of an imperfectly filled left ventricle and of impairing its aspirative power in diastole on the pulmonic circuit. It is, therefore, only in a certain phase 